one day combat gout but is really a proof of principle. "This is honestly where we need to have synthetic biologists working," he says. "Generating potential therapeutics is the most relevant thing we can contribute to society."

\section{Courting the financiers}

For all its potential, fewer than ten synthetic biology labs work on clinical applications. "There has to be more investment from the venture community and other players to support this research, and that hasn't happened yet," says Sridaran Natesan, head of external innovation and partnering for the French pharma giant Sanofi in the US northeast. "It's too long term, at least in people's minds, so it's a risky investment."

Still, he adds that Sanofi is "actively thinking about investing in some promising areas and working with key guys in the field." Earlier this year, the company granted $\$ 150,000$ to Ron Weiss's synthetic biology lab at the Massachusetts Institute of Technology (MIT) in Cambridge, Massachusetts, as part of its Biomedical Innovation Program with the university. Weiss, director of the MIT Synthetic Biology Center, plans to create gene circuits that can be introduced into human fibroblasts to make them insulinproducing beta cells in response to a specific signal.

Meanwhile, Noubar Afeyan, chief executive of Flagship Ventures, a Cambridge, Massachusetts-based venture capital firm and a founder of the growing biofuel company LS9, is now searching for the right therapeutic to take on. He estimates that a biotech startup would need at least $\$ 100$ million to spin an academic synthetic therapeutic into a technology with commercial value-and that's well before a pharmaceutical company can develop it into a product ready for clinical trials. So, Afeyan is cautious. "What we would need is to feel better about the safety prospect and find a compelling first application," he explains.

\section{Hacking a way forward}

Many synthetic biologists echo Afeyan's apprehensions. Chris Voigt, a bioengineer at MIT and one of the leaders in the field, says that synthetic biology still has to prove it can work consistently in mammalian cells. "One of the core principles of synthetic biology is that if you characterize part A and characterize part $B$, you can predict how they'll behave together, and in mammalian cells that's pretty tricky," he says.

Placing a single gene in an exact desired spot in the human genome can be difficult

\title{
Bioengingeering bacteria for a cure-it's not that easy
}

Chris Voigt opens a glass case and delicately lifts a chocolate brown seashell covered with a naturally occurring pattern of uniform white triangles. "From a very simple set of genetic instructions, you get a very complex pattern, see?" He then points to another shell that looks as if it were etched with letter-like symbols. These patterns on shells have inspired the MIT bioengineer. They suggest that genetic systems can contain an almost computer-like logic, and with a few elegant lines of genetic code an organism can be made to behave almost mathematically.

With that logic in mind, Voigt, in collaboration with Chris Anderson and Adam Arkin at the University of California-Berkeley, developed a genetic circuit in Escherichia coli that causes the bacteria to hunt and destroy cancer ${ }^{9}$. The bacterial cells are programmed to circulate through the bloodstream and detect the low oxygen levels in tumors. Once in contact, the bacteria respond by producing a protein called invasin, which causes them to invade the tumor cells.

Illustrating the reliability of the system, when Voigt and his collaborators recovered the bacteria from the cancer cells, all the bacteria they found had expressed the invasin protein. As a next step, the E. coli could be programmed to release a cytotoxin to kill the cancer.

Theirs is just one of several projects aiming to turn microorganisms into disease fighters that can then be injected into the human body. Other groups have turned to Salmonella for similar cancer-fighting prospects. But, after seven years of working on tumor-invading bacteria, Voigt and his collaborator Chris Anderson, have given up. "It was only six months ago that we said, 'let's not do this anymore'," Anderson says.

Anderson explains that his lab had successfully designed a circuit within the $E$. coli to target and attack cancer cells, but the immune system slaughtered the bacteria before they could act. To prolong their survival, his lab inserted genes to change the bacteria's surface proteins. "We ended up in highly uncharted territory," he says, and the gene inserts failed to keep the bacteria alive.

"We discovered so many fundamentally missing abilities. It's a problem that is more difficult than our toolkit can handle," Anderson says. "At the time, it seemed like you'd be able to make stable devices out of these very noisy [DNA] parts. The result is you really need to understand how all the bits and pieces fit."

In the aftermath, Anderson has moved onto finding a better way to assess and define which gene parts would work best in a circuit, whereas Voigt has refocused his attention on using synthetic biology to produce small molecules for new—nonliving—-medicines. —DG

even with the latest technologies. And trying to then insert multiple genes that work together makes the chances for success even more difficult. "The way you deal with mammalian cells now is by luck," says Pamela Silver, a system biologist at Harvard Medical School in Boston.

Almost all the research in the field of synthetic biology remains on the level of proof of concept. For now, many experts are watching to see how the US Food and Drug Administration evaluates gene therapy products for a signal of how regulators might view even more elaborate therapies involving entire gene circuits down the road. "I think once the FDA gets comfortable with and eventually approves a gene therapy approach, then it's an incremental step to increasingly put in more than just single genes," Afeyan says.

\section{Daniel Grushkin is a science journalist in Brooklyn, New York, and the cofounder of Genspace, a community lab and education space that focuses on synthetic biology.}

1. Chen, Y.Y. et al. Proc. Natl. Acad. Sci. USA 107, 85318536 (2010).

2. Danino, T. et al. Nature 463, 326-330 (2010).

3. Warren, L. et al. Cell Stem Cell 7, 618-630 (2010).

4. Gardner, T.S. et al. Nature 403, 339-342 (2000).

5. Kramer, B.P. et al. Nat. Biotechnol. 22, 867-870 (2004).

6. Ausländer S. et al. Nature 487, 123-127 (2012).

7. Xie, Z. et al. Science 333, 1307-1311 (2011).

8. Kemmer, C. et al. Nat. Biotechnol. 28, 355-360 (2010).

9. Anderson, J.C. et al. J Mol Biol. 355, 619-627 (2006). 